\title{
Management of acute attacks of hereditary angioedema: potential role of icatibant
}

\author{
This article was published in the following Dove Press journal: \\ Vascular Health and Risk Management \\ 3 September 2010 \\ Number of times this article has been viewed
}

\section{Hilary J Longhurst}

Department of Immunology, Barts and The London NHS Trust, London, UK
Correspondence: Hilary J Longhurst Department of Immunology, Barts and The London NHS Trust, Pathology and Pharmacy Building, 80 Newark Street, London EI 2ES, UK

Email hilary.longhurst@bartsandthelondon. nhs.uk

\begin{abstract}
Icatibant $\left(\right.$ Firazyr $\left.^{\circledR}\right)$ is a novel subcutaneous treatment recently licensed in the European Union for acute hereditary angioedema. Hereditary angioedema, resulting from inherited partial $\mathrm{C} 1$ inhibitor deficiency, is a disabling condition characterized by intermittent episodes of bradykinin-mediated angioedema. Icatibant blocks bradykinin B2 receptors, attenutating the episode. Randomized double-blind, placebo-controlled trials of icatibant, showed significant superiority over oral tranexamic acid in 74 European patients and a trend to improvement in a similar US trial comparing icatibant with placebo in 55 patients. Outcomes for several endpoints did not reach significance in the US trial, perhaps because of low participant numbers and confounding factors: a further trial is planned. Open label studies have shown benefit in multiple treatments for attacks at all sites. Approximately $10 \%$ of patients require a second dose for re-emergent symptoms, usually 10 to 27 hours after the initial treatment. Its subcutaneous route of administration, good tolerability and novel mode of action make icatibant a promising addition to the limited repertoire of treatments for hereditary angioedema.
\end{abstract}

Keywords: hereditary angioedema, bradykinin, icatibant, C1 inhibitor deficiency

\section{Hereditary angioedema: clinical features and current management of acute attacks}

Hereditary angioedema (HAE) is an autosomal dominant disorder resulting from a partial deficiency of $\mathrm{C} 1$ inhibitor $(\mathrm{C} 1-\mathrm{INH})$. Those affected experience intermittent cutaneous or mucosal swellings or 'attacks', lasting between 1 and 5 days. ${ }^{1,2}$ Swellings affecting the skin are typically painless but may cause disfigurement, or difficulty driving or operating machinery if hands or feet are involved. Cutaneous swelling of the genital area may occasionally lead to retention of urine. Intra-abdominal edema, affecting bowel segments or viscera, is usually very painful, may be associated with vomiting and/or diarrhea, is occasionally mistaken for a surgical emergency and typically leads to temporary disablement, with full recovery after several days. ${ }^{3,4}$ By contrast, laryngeal attacks may be fatal. Lifetime fatality rates have been estimated at between $10 \%$ and $30 \%{ }^{5}$ and $25 \%$ of families surveyed in the European HAE register reported an HAE-related fatality, almost exclusively caused by laryngeal edema. ${ }^{6,7}$ Because the episode fatality rate of laryngeal edema is relatively low, patients may experience many such attacks which resolve spontaneously or with treatment, and therefore may fail to treat laryngeal symptoms as a medical emergency. Conversely patients may be so fearful of laryngeal swelling that they are unwilling to risk being unable to obtain emergency treatment by traveling any distance from their local hospital, resulting in social and employment difficulties. 
Prophylaxis for HAE attacks is available; either with attenuated androgens which increase hepatic production of endogenous $\mathrm{C} 1$ inhibitor, or by antifibrinolytics such as tranexamic acid or $\varepsilon$-aminocaproic acid (EACA) which may exert a C1-INH sparing effect. ${ }^{9,10}$ However, efficacy of these agents is variable and most patients continue to experience intermittent swellings albeit at a reduced frequency. Attenuated androgens are associated with androgenic side-effects such as amenorrhea, weight gain, mood changes or hirsutism; and hepatitis or the development of adenomas., ${ }^{9,11,12}$ Therefore many patients find prophylactic agents insufficiently effective or have unacceptable side-effects.

For acute HAE attacks, tranexamic acid is of very limited benefit and attenuated androgens are not effective. Until recently, $\mathrm{C} 1-\mathrm{INH}$ has been the sole option for acute treatment. $\mathrm{C} 1-\mathrm{INH}$ is purified from the pooled plasma of volunteer donors and is subject to one or more additional treatments to minimize risk of pathogen transmission. Current C1-INH concentrates have proven safe and effective in double-blind placebo-controlled trials $\mathrm{s}^{9,13-18}$ and in clinical practice ${ }^{14,19-22}$ $\mathrm{C} 1-\mathrm{INH}$ is also effective in prophylaxis. ${ }^{23-25}$ Availability has been limited by licensing status, expense, its human source and requirement for intravenous administration, and until recently it has not been available at all in several countries, including the US.

Icatibant (Firazyr ${ }^{\circledR}$; Shire), a bradykinin B2 receptor inhibitor, was licensed in the EU, Switzerland, Lichtenstein and Iceland in July 2008 for treatment of acute HAE-related swellings. A concurrent marketing application was turned down by the US Food and Drug administration (FDA), pending the results of a confirmatory placebo-controlled phase III trial. Icatibant has orphan drug status in Australia, EU, Switzerland and the US.

This review examines the evidence supporting use of this agent and considers its place in management of hereditary angioedema.

\section{Pathophysiology of HAE and role of iatibant}

$\mathrm{C} 1$ inhibitor is a serpin whose principal function is the regulation of local inflammation. It inhibits $\mathrm{C} 1 \mathrm{r} / \mathrm{s}$ in the classical complement pathway, kallikrein and factors XI and XII (Hageman factor) of the contact pathway and plasmin of the thrombolytic pathway. It also has a role in the control of the alternative and mannan binding ligand pathways. ${ }^{26}$ Genetic mutations of the C1-INH gene on chromosome 11 give rise to reduced levels (HAE type I) or reduced function (HAE type II) of $\mathrm{C} 1$ inhibitor. At times of physiological stress, patients with HAE may have insufficient endogenous local $\mathrm{C} 1-\mathrm{INH}$, resulting in excessive local vasodilatation and edema. Estrogens ${ }^{27}$ trauma, ${ }^{6,28,29}$ minor infection ${ }^{29,30}$ or psychological stress, ${ }^{31}$ may precipitate attacks; however, for the majority of attacks, the trigger is unknown. ${ }^{26,32}$

Current evidence favors bradykinin as the principal mediator of edema in HAE: Patients with HAE have raised plasma levels of bradykinin compared with normal controls. Levels increase further during attacks. Local bradykinin concentrations are much higher at the site of swelling than at unaffected sites ${ }^{26,32-36}$ One unusual family had a $\mathrm{C} 1$ inhibitor mutation with preserved kallikrein inhibitory function and presumably normal bradykinin. Members of this family had low classical pathway complement levels, typical of HAE, but no swellings, presenting instead with lupus (secondary to acquired deficiency of early classical pathway complement components). ${ }^{37}$

Bradykinin acts on two types of receptors. Inducible B1 receptors probably mediate pain and possibly erythema, while activation of constitutive B2 receptors causes local vasodilatation and edema. Icatibant is a synthetic decapeptide and competitive inhibitor of bradykinin B2 receptors. It exerts its action in HAE by antagonizing the vasodilatory effect of excess bradykinin.

\section{Chemistry}

The active decapeptide of icatibant; H-D-Arg-Arg-Pro-HypGly-Thi-Ser-D-Tic-Oic-Arg-OH is synthesized in a solid phase peptide synthesis process. Thus, unlike $\mathrm{C} 1$ inhibitor, it does not contain human or other animal material. Icatibant is stable for up to 24 months at $5^{\circ} \mathrm{C}$, and for up to 6 months at $25^{\circ} \mathrm{C}$. This relatively long shelf life is important; current advice is that patients should keep at least one acute treatment at home and the majority of patients require only infrequent treatments. ${ }^{38,39}$ It is supplied as a $3 \mathrm{~mL}$ pre-filled syringe for subcutaneous injection. ${ }^{40}$

\section{Pharmacokinetics}

Icatibant is a specific competitive antagonist with similar affinity to bradykinin (1-10 $\mathrm{nM}$ ) for the $\mathrm{B} 2$ receptor, while affinity for the B1 receptor is 100 -fold lower. In vitro studies did not reveal activity on other receptors or enzymes, including the cytochrome p450 system, thus major drug interactions were not predicted by these preclinical studies. Icatibant is rapidly absorbed after subcutaneous administration, although individuals may show variation in its absorption rate of up to $25 \%$. Maximum concentrations are reached within 30 minutes and bioavailability is high at around $97 \% .^{40,41}$ 
Relatively fast absorption is essential since rapid symptom control is required. Intravenous administration was investigated but did not offer pharmacokinetic benefit and was less convenient than subcutaneous injection. Icatibant has low protein binding at around $44 \%$ and the volume of distribution is 20 to $25 \mathrm{~L}$, consistent with distribution to include sites of swelling. Animal studies indicate that icatibant is poorly distributed into adipose tissue and does not appear to cross the blood brain barrier. However, it does cross the placenta and is excreted in breast milk in rats. ${ }^{40}$

Icatibant is metabolized in the liver by cleavage to 2 smaller peptides; metabolites $(90 \%)$ and intact icatibant $(10 \%)$ are excreted via the kidney. Half-life of icatibant and its metabolites is 1 to 2 hours. Pharmacokinetics appears unaffected by liver and renal impairment in animal studies. Human studies of icatibant, for resistant ascites in patients with cirrhosis of the liver, some of whom had concomitant renal impairment did not raise safety concerns. ${ }^{40}$ Icatibant pharmacokinetics do not appear to depend on weight or gender but clearance is reduced in the elderly with area under the curve increased by $5 \%$ to $60 \%$ in an 80 -year-old compared with a 40 -year-old patient. ${ }^{40}$

\section{Pharmacodynamics}

Bradykinin inhibition studies with healthy human volunteers showed a mean EC50 (concentration at which $50 \%$ of the measured effect of bradykinin was inhibited) of 7.3 to $10.8 \mathrm{~nm}$ depending on the method used. Based on these preclinical data and the results of an open label trial (discussed later) $)^{40,42} 30 \mathrm{mg}$ was selected as the optimum subcutaneous dose. Since the duration of action of icatibant appeared relatively independent of dose within the therapeutic range, administration of a second (and third) $30 \mathrm{mg}$ dose when indicated appeared more logical than use of a higher single dose.

In rodents, partial bradykinin agonist activity was apparent at supra-therapeutic doses of $3.2 \mathrm{mg} / \mathrm{kg}$ or higher. ${ }^{40}$ Concentrations sufficient to produce these effects may occur locally and may account for local reactions after subcutaneous injection. Except in the case of overdose, they are otherwise unlikely to occur in clinical use.

\section{Clinical data}

One pilot unblinded and 2 double-blinded studies have been completed. Patients taking part in the double-blind studies were treated for subsequent attacks with open label icatibant.

The phase II open label dose finding study involved 20 attacks in 15 patients, treated with single intravenous (iv) infusions or subcutaneous (sc) injections $(0.4 \mathrm{mg} / \mathrm{kg}$ over 30 minutes or 2 hours; or $0.8 \mathrm{mg} / \mathrm{kg}$ [iv] over 30 minutes; or $30 / 45 \mathrm{mg}[\mathrm{sc}]) .^{40,43}$

The phase III trials were randomized, double-blinded trials comparing a single $30 \mathrm{mg}$ sc dose of icatibant with placebo (For Angioedema, Subcutaneous Treatment (FAST)-1; US, Canada, Argentina, and Australia) in 56 patients; or the active comparator, tranexamic acid (FAST-2; EU and Israel) in 74 patients. An additional 10 patients with laryngeal edema were treated with open label icatibant. ${ }^{40,44}$ One further patient in the US study experiencing onset of laryngeal symptoms after treatment with placebo was given rescue treatment with icatibant. The phase III studies included open label phase extensions for treated patients and for those enrolled but not treated prior to the end of the double-blind phase. ${ }^{40}$

In all trials, outcomes were measured using a $100 \mathrm{~mm}$ visual analog scale (VAS, detailed in Figure 1) reported by the patient for the main, and (in the phase II studies) secondary symptoms. In the phase III studies, additional outcome assessments were made by patient and physician, using a 5 or 7 point symptom score for individual HAE-related symptoms and global wellbeing respectively.

In the phase II study, patients with a variety of peripheral or abdominal attacks were treated at between 6 and 10 hours after the onset of symptoms. Results suggested that subcutaneous administration of icatibant was at least as effective as intravenous, with median time to first response of around 1 hour (iv) or 30 minutes (sc); 30\% improvement (time to onset of resolution; TOR30) at 2 to 5 hours and almost complete $(90 \%)$ resolution (TOR90) at around 8.5 to 16 hours. No clear differences were seen over the dose range tested. On this basis, $30 \mathrm{mg}$ sc was selected for further study. ${ }^{43}$

Both phase III studies included adults ( $\geq 18$ years) with HAE, experiencing a moderate or severe attack at any site. Study treatment was administered within 6 hours of the attack becoming moderate in severity ( $\geq 3 / 10$ on the VAS scale). Those with laryngeal symptoms were treated with icatibant on an open label basis, while those with attacks at other sites (the majority) were randomized to $30 \mathrm{mg}$ icatibant subcutaneously into the anterior abdominal wall, or comparator (oral tranexamic acid $1 \mathrm{~g} 3$ times daily for 3 days in FAST-2; placebo in FAST-1) in a double-blind fashion. The primary endpoint was the time to onset of symptom relief, as measured by sustained improvement of at least $30 \%$ on the VAS scale (TOR30), assessed for the principal symptom (for example cutaneous swelling or abdominal pain). Secondary endpoints were response rate at 4 hours 


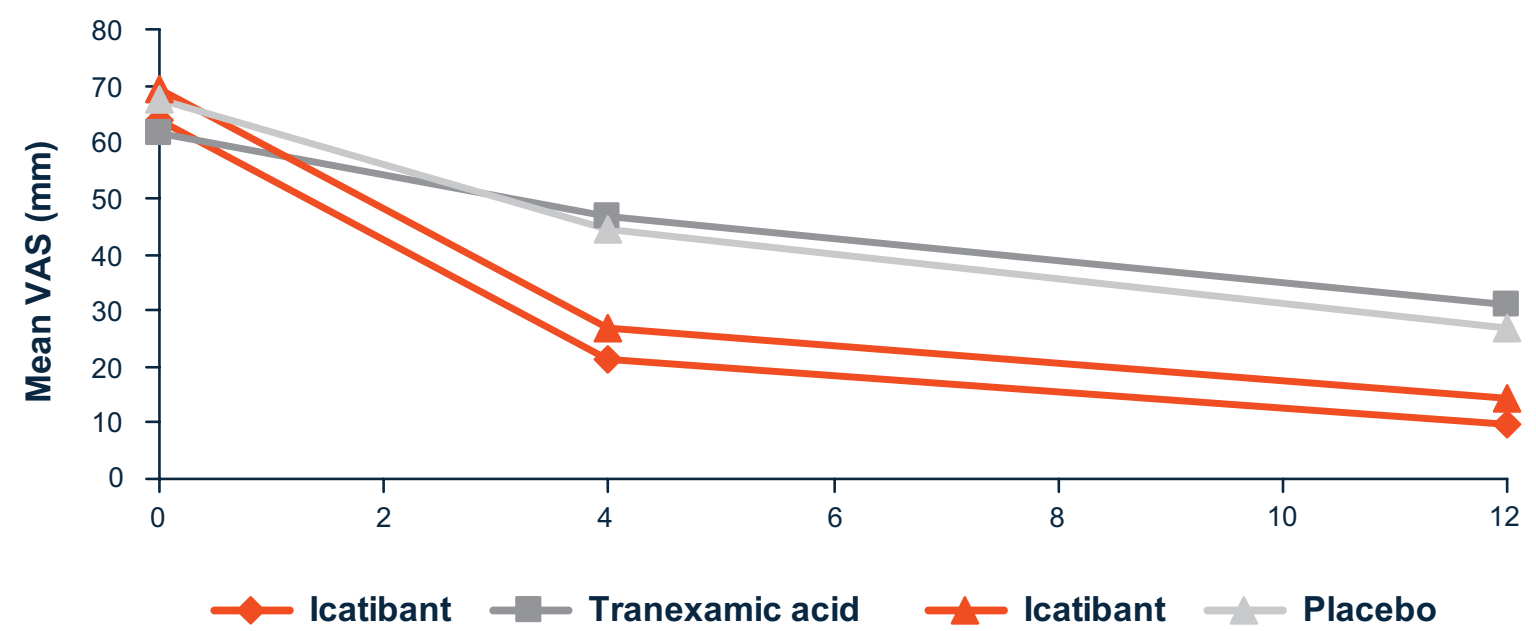

Figure I Improvement of symptom severity at 4 hours and I 2 hours (FAST-I and FAST-2). ${ }^{40}$

Notes: When completing the visual analog score (VAS), the patient is asked to put a mark on a $100 \mathrm{~mm}$ line, according to the severity of each symptom. The left end of the line represents absence of the symptom and the right end of the line represents the most severe symptom imaginable. Distance of the mark along the line gives a measure of symptom severity. Triangles represent FAST-I; quadrilaterals represent FAST-2.

after treatment, time to relief of secondary symptoms, time to start of improvement according to patient, time to observable regression of visible swelling, global assessment and overall patient improvement and, at week 24 , a patient satisfaction questionnaire.

In both studies, patients improved more quickly with icatibant, with a median time to onset of symptom relief (TOR30) of 2.0 hours compared with 12.0 hours for tranexamic acid (FAST-2) and 2.5 compared with 4.6 hours for placebo (FAST-1). The difference was statistically significant for FAST-2 but not for FAST-1. Improvement of the secondary endpoints was faster in the icatibant treated groups. The improvement was significant for the majority of endpoints in FAST-2 but not FAST-1, where parameters showed a non-significant trend to improvement.

Figure 1 shows the mean VAS values over time for the symptom used for the primary endpoint.

\section{Rescue medication}

More rescue medication, including narcotic and other painkillers, was administered to patients who received placebo or tranexamic acid compared with those who received icatibant. In FAST-1, 11 patients randomized to placebo required rescue medication within 12 hours and a further 14 required rescue medication within 48 hours, compared with 3 patients in 12 hours and 6 within 48 hours for patients receiving icatibant. Similarly in FAST-2, 5 patients randomized to tranexamic acid required rescue medication within 12 hours and 11 required rescue medication within 48 hours, compared with 0 patients in 12 hours and 5 within
48 hours for patients receiving icatibant. ${ }^{44.45}$ The need for additional rescue medication suggests inferior symptom control in the comparator arm, and conversely may have contributed to the lack of significance $(P>0.05)$ in some parameters of the FAST-1 trial.

\section{Open label treatments}

Data are available on a further 118 patients experiencing 597 HAE attacks treated with icatibant in the open label extensions of FAST-1 and FAST-2. Of these, 59 (9.9\%) patients' symptoms recurred, all but 3 patients more than 10 hours after icatibant administration. Of these patients $60.9 \%$ were treated with a further injection of icatibant. Four patients $(0.7 \%$ of the original group) were treated with a third injection of icatibant. ${ }^{40}$

More recently Malbrán et al have described their experience of treating 163 attacks in 19 patients in Argentina. Time to subjective improvement was an average of 37.9 minutes. One of 102 patients analyzed received a second dose because of insufficient response at 6 hours, 13 of 102 (12.7\%) reported an exacerbation of symptoms within 48 hours, of whom 6 received a second dose of icatibant with relief. ${ }^{46}$ Similarly, Reshef et al report mean (SE) times to response for 40.6 (18.3) minutes for 25 abdominal attacks and 57.7 (26.4) minutes for 38 cutaneous attacks in 15 patients. $^{47}$

\section{Laryngeal attacks}

A total of 61 laryngeal attacks of all severities, in 36 patients, have been treated during the FAST trials, including the open label extensions. ${ }^{40,44}$ Time to first symptom improvement 
according to the patient ranged from 0.3 to 3.6 hours (FAST-2) and 0.3 to 2.4 hours (FAST-1). Requirement for a second icatibant injection appeared similar to that required for attacks at other sites at $10 \%$ ( 5 of 50 eligible attacks). One patient with laryngeal edema required intubation 5 minutes after the administration of icatibant. ${ }^{40}$ However, neither icatibant nor replacement therapy with $\mathrm{C} 1$ inhibitor concentrate would be expected to take effect within this timescale. Although not directly comparable, response time seems similar to that reported for $\mathrm{C} 1$ inhibitor treatment, although recurrent angioedema seems to be less frequent with $\mathrm{C} 1$ inhibitor. ${ }^{18,19}$

\section{Multiple attacks}

Efficacy of icatibant appears similar in patients receiving up to 110 repeated treatments for multiple attacks. For each attack, the requirement for a second or third dose of icatibant remained constant at around $10 \%$ or $1 \%$ respectively. There is no method for measuring icatibant antibodies but the low antigenic potential in animal studies (as seen with other short peptides) and the multiple treatment data provide some reassurance that this is unlikely to be a major problem. ${ }^{40}$

\section{Recurrent attacks}

The observed need for more than one injection in $10 \%$ is potentially of concern. Recurrent attacks are likely to be a consequence of the short half-life of icatibant, although continuing overactivation of other inflammatory pathways controlled by $\mathrm{C} 1$ inhibitor may contribute. Further information on recurrent attacks is available from Bork's dose-finding study. Of the $20 \mathrm{HAE}$ attacks, 5 attacks in 4 patients recurred between 14 and 27 hours after the initial treatment, albeit not all treatments were at optimal dose or route. Four attacks recurred at the same site and one at a different site. All were mild and were treated with $\mathrm{C} 1$ inhibitor. ${ }^{42}$ These observations are similar to experience in UK, where recurrence generally occurs the following day and is of slow onset, usually at the same site. We have observed that recurrence appears much more likely in patients with very frequent attacks. ${ }^{48}$ Thus, it is important that patients are aware of the possibility of recurrence and have a plan for this eventuality.

\section{Side effects Injection site reactions}

Most patients receiving subcutaneous icatibant experience injection site reactions. Erythema, swelling and pain at the injection site lasted from 10 minutes to several hours. However, the reactions are generally tolerated well without need for additional analgesia. ${ }^{42,48}$ These symptoms are most likely caused by partial agonist activity.

\section{Systemic reactions}

In clinical studies, the majority of the adverse events appeared to be related to the HAE. A total of 1002 subjects have received icatibant, by the intravenous, subcutaneous, intranasal, inhalational or intra-articular routes, in trials for a variety of indications, with adverse reaction rate (excluding local reactions) similar to placebo. ${ }^{40}$

Bradykinin is important in protecting ischemic tissues; animal models suggesting poorer outcomes in myocardial ischemia/infarction after icatibant treatment. For this reason icatibant is not recommended for use in the presence of acute cardiac or brain ischemia. Bradykinin antagonism might be expected to increase blood pressure. However, no hypertensive effect at therapeutic doses was seen in clinical or animal trials. Because of icatibant's short half-life and intermittent use, it would be unlikely to exert a chronic hypertensive effect.

Icatibant has been used in a trial for resistant ascites in liver cirrhosis, which included participants with severe liver and renal impairment, appearing well tolerated in this vulnerable group. ${ }^{40}$

\section{Discussion}

Icatibant is the first new treatment to be made available for HAE since the advent of $\mathrm{C} 1$ inhibitor over 25 years ago,

Table I Recurrent symptoms reported in dose finding pilot study of icatibant ${ }^{43}$

\begin{tabular}{lllll}
\hline $\begin{array}{l}\text { Patient age } \\
\text { (years)/sex }\end{array}$ & $\begin{array}{l}\text { Site of primary } \\
\text { attack }\end{array}$ & $\begin{array}{l}\text { Time after administration } \\
\text { of icatibant of recurrence } \\
\text { (hours) }\end{array}$ & $\begin{array}{l}\text { Severity of } \\
\text { recurrence }\end{array}$ & $\begin{array}{l}\text { Site of } \\
\text { recurrence }\end{array}$ \\
\hline $43 \mathrm{~F}$ & Abdominal & 14 & Unknown & Abdominal \\
$47 \mathrm{M}$ & Abdominal & 17 & Unknown & Abdominal \\
$31 \mathrm{M}$ & Skin/abdominal & 20 & Mild & Skin/abdominal \\
$53 \mathrm{~F}$ & Skin/abdominal & 20 & Unknown & Skin \\
\hline
\end{tabular}


and is a very welcome addition to the limited therapeutic options available for this disorder. It has not yet been formally evaluated in other bradykinin-mediated angioedemas. However, it would be a logical choice in acquired angioedema due to $\mathrm{C} 1$ inhibitor deficiency, especially where large doses of $\mathrm{C} 1$ inhibitor would otherwise be required. ${ }^{23,49}$ It could potentially be of use in angiotensin converting enzyme (ACE) inhibitor-related swelling, and in HAE3, which in some cases at least, is associated with factor XII mutations and consequent bradykinin overproduction, ${ }^{50}$ although it has not been tested for these indications. Other medications in development for HAE include ecallantide (DX88), a kallikrein inhibitor. Like icatibant, it has the advantage of subcutaneous administration and has shown promise in placebo controlled trials. Ecallantide inhibits kallikrein, thus reducing bradykinin production and preventing further swelling. ${ }^{51}$ It is currently unlicensed. Rhucin, a recombinant $\mathrm{C} 1$ inhibitor, given intravenously, is also currently unlicensed. ${ }^{52-54}$

There have been no head-to-head trials comparing icatibant with $\mathrm{C} 1$ inhibitor concentrate, or other acute treatments. Studies of emergency treatment where patients need to travel, sometimes for several hours, to get treatment in the trial center are logistically difficult. This, together with the low prevalence of HAE, makes it unlikely that such trials will ever take place. While not being directly comparable, results of studies of $\mathrm{C} 1$ inhibitor in acute $\mathrm{HAE}$ suggest that the icatibant and $\mathrm{C} 1$ inhibitor are broadly similar in terms of onset of relief and time to complete resolution of symptoms. ${ }^{15-18,40}$

In the European (FAST-2) trial, icatibant showed a significant benefit compared with tranexamic acid. By contrast, while showing a marked trend in favor of icatibant in the US (FAST-1) trial, the difference between icatibant and placebo did not reach significance for several endpoints, including the primary end point. ${ }^{40}$ This is likely to result from underpowering, since the low numbers were randomized for a treatment where delayed and variable responses are expected, and where the outcome measures are subjective. Additionally the use of intravenous rehydration, pain relief - including with opiates - and other symptomatic measures was greater in the placebo group. These almost certainly contributed to the greater than expected improvement in the placebo group, which was of sufficient magnitude to reach the endpoint of $30 \%$ improvement in several cases. ${ }^{40}$ The ongoing FAST-3 trial will provide additional efficacy data.

Icatibant, with a half-life of around 2 hours, is short-acting compared to $\mathrm{C} 1$ inhibitor (half-life 30-64 hours), 5,26,32,42 and to the duration of a typical acute attack, which is 1 to 5 days. ${ }^{1,4}$ This is the likely explanation for recurrent swellings. In practice, recurrence appears a relatively unusual event with only around $10 \%$ of attacks requiring more than 1 , and $1 \%$ requiring more than 2 injections. Since icatibant does not replace $\mathrm{C} 1$ inhibitor, attenuate contact pathway or complement activation, or reduce bradykinin production, this may at first appear surprising. Icatibant stops the progression of edema, and allows physiological resolution. Edema may recur if the effect of icatibant wears off while bradykinin levels are still elevated. However, the recurrent edema will often be subclinical since fluid accumulated does not reach a sufficient volume to produce symptoms before natural resolution of the attack.

Treatment of acute HAE with $\mathrm{C} 1$ inhibitor is most effective when given early. ${ }^{20}$ However, $\mathrm{C} 1$ inhibitor's intravenous route of administration can result in delays in gaining access to treatment. This has been partially addressed by the development of home therapy/self administration programs. ${ }^{24,55-57}$ Self-administration of $\mathrm{C} 1$ inhibitor requires a high degree of patient motivation and support, and the majority of patients who have only infrequent attacks may be less motivated to undergo the necessary training. This is important, since failure to access emergency treatment in a timely manner is the major contributor to the employment, educational and social difficulties associated with HAE, as well as to mortality. The availability of a licensed subcutaneous treatment will facilitate administration by local and community-based healthcare staff without requirement for up to date intravenous skills. Assuming the reassuring safety record of icatibant is confirmed in clinical use, the true place for icatibant seems likely to be in self-administration, where it has potential to address a significant unmet need. In this respect, it may have an advantage over ecallantide, which has been associated with anaphylactoid-like symptoms. ${ }^{58}$

Home therapy programmes for children are less well established, perhaps due to the lower frequency of acute attacks prior to adolescence ${ }^{59}$ or anticipated greater technical difficulties with intravenous access. There is a lack of effective prophylactic options for children since attenuated androgens are not recommended pre-puberty. ${ }^{38,39}$ For the few children who have frequent attacks, a subcutaneous acute treatment would be an attractive option, although the pain associated with icatibant injections may be a problem. Repeated doses of icatibant administered to juvenile animals resulted in reversible delay in sexual maturation. ${ }^{40}$ Further information would be necessary before icatibant could be recommended for trials in this age group. 
Attenuated androgens are contraindicated in pregnancy. Therefore many pregnant women experience an increased frequency of attacks because of lack of effective oral prophylaxis and hormonal changes. ${ }^{39,60}$ Animal studies have shown that icatibant does not appear to have genetic toxicity nor cause structural damage to embryos. ${ }^{40}$ No human data are available and therefore $\mathrm{C} 1$ inhibitor concentrate, for attacks or prophylactically, must remain the treatment of choice for this difficult to treat group.

Despite only recently gaining a licence in many EU countries and in the US, C1 inhibitor has been used extensively for HAE and has an impressive record. ${ }^{22,54,61,62}$ It seems likely that both $\mathrm{C} 1$ inhibitor and icatibant will be used, perhaps at different times in the same patient, according to circumstances. The advent of a second, complementary treatment option is a major step forward for this orphan disease.

\section{Disclosure}

Dr Hilary J Longhurst and department colleagues have received sponsorship for educational purposes, have been paid for providing consultancy services, and have taken part in clinical trials sponsored by Jerini/Shire, CSL, Dyax, and Pharming.

\section{References}

1. Agostoni A, Cicardi M. Hereditary and acquired C1-inhibitor deficiency: biological and clinical characteristics in 235 patients. Medicine (Baltimore). 1992;71(4):206-215.

2. Nzeako UC, Frigas E, Tremaine WJ. Hereditary angioedema: a broad review for clinicians. Arch Intern Med. 2001;161(20):2417-2429.

3. Bork K, Meng G, Staubach P, Hardt J. Hereditary angioedema: new findings concerning symptoms, affected organs, and course. Am J Med. 2006;119(3):267-274.

4. Bork K, Staubach P, Eckardt AJ, Hardt J. Symptoms, course, and complications of abdominal attacks in hereditary angioedema due to C1 inhibitor deficiency. Am J Gastroenterol. 2006;101(3):619-627.

5. Agostoni A, Aygoren-Pursun E, Binkley KE, Blanch A, Bork K, Bouillet L, et al. Hereditary and acquired angioedema: problems and progress: proceedings of the third $\mathrm{C} 1$ esterase inhibitor deficiency workshop and beyond. J Allergy Clin Immunol. 2004;114(3 Suppl):S51-S131.

6. Bork K, Hardt J, Schicketanz KH, Ressel N. Clinical studies of sudden upper airway obstruction in patients with hereditary angioedema due to $\mathrm{C} 1$ esterase inhibitor deficiency. Arch Intern Med. 2003;163(10):1229-1235.

7. Bork K, Ressel N. Sudden upper airway obstruction in patients with hereditary angioedema. Transfus Apher Sci. 2003;29(3):235-238.

8. Gelfand JA, Sherins RJ, Alling DW, Frank MM. Treatment of hereditary angioedema with danazol. Reversal of clinical and biochemical abnormalities. N Engl J Med. 1976;295(26):1444-1448.

9. Blohme G. Treatment of hereditary angioneurotic oedema with tranexamic acid. A random double-blind cross-over study. Acta Med Scand. 1972;192(4):293-298.

10. Frank M, Gelfand JA, Alling DW, Sherins RJ. Epsilon aminocaproic acid for hereditary angioedema. N Engl J Med. 1977;296(21): 1235-1236.

11. Bork K, Bygum A, Hardt J. Benefits and risks of danazol in hereditary angioedema: a long-term survey of 118 patients. Ann Allergy Asthma Immunol. 2008;100(2):153-161.
12. Cicardi M, Castelli R, Zingale LC, Agostoni A. Side effects of long-term prophylaxis with attenuated androgens in hereditary angioedema: comparison of treated and untreated patients. J Allergy Clin Immunol. 1997;99(2):194-196.

13. Kunschak M, Engl W, Maritsch F, Rosen FS, Eder G, Zerlauth G, et al. A randomized, controlled trial to study the efficacy and safety of $\mathrm{C} 1$ inhibitor concentrate in treating hereditary angioedema. Transfusion. 1998;38(6):540-549.

14. Waytes AT, Rosen FS, Frank MM. Treatment of hereditary angioedema with a vapor-heated $\mathrm{C} 1$ inhibitor concentrate. $N$ Engl $J$ Med. 1996;334(25):1630-1634.

15. Bernstein JA, Levy R, Wasserman RL, Bewtra A, Hurewitz D, Obtulowicz K, et al. Treatment of acute abdominal and facial attacks of hereditary angioedema (HAE) with human $\mathrm{C} 1$ esterase inhibitor (C1-INH): results of a global, multicenter, randomized, placebo-controlled, phase I/II study (IMPACT 1). [Abstract]. J Allergy Clin Immunol. 2008;121:795.

16. Craig TJ, Wassermann RL, Levy R, Bewtra A, Hurewitz D, Peters D, et al. C1-esterase inhibitor (C1-INH) -standard of care for the treatment of acute attacks in hereditary angioedema (HAE): initial results of an ongoing, prospective, open-label study in Normth America (IMPACT 2). [Abstract]. J Allergy Clin Immunol. 2008;121:S98-S99.

17. Zuraw BL, Schaefer O, Grant JA, et al. Results of a randomized doubleblind controlled study of nanofiltered C1-inhibitor for the treatment of HAE attacks. [Abstract] ACAAI poster presentation, Dallas TX USA. 9-11-2007.

18. Craig TJ, Levy R, Wasserman RL, Bewtra A, Hurewitz D, Obtulowicz K, et al. Efficacy of human $\mathrm{C} 1$ esterase inhibitor concentrate compared with placebo in acute hereditary angioedema attacks. J Allergy Clin Immunol. 2009;124(4):801-808.

19. Bork K, Barnstedt SE. Treatment of 193 episodes of laryngeal edema with $\mathrm{C} 1$ inhibitor concentrate in patients with hereditary angioedema. Arch Intern Med. 2001;161(5):714-718.

20. Bork K, Meng G, Staubach P, Hardt J. Treatment with C1 inhibitor concentrate in abdominal pain attacks of patients with hereditary angioedema. Transfusion. 2005;45(11):1774-1784.

21. Bork K, Staubach P, Hardt J. Treatment of skin swellings with C1-inhibitor concentrate in patients with hereditary angio-oedema. Allergy. 2008;63(6):751-757.

22. Farkas H, Jakab L, Temesszentandrasi G, Visy B, Harmat G, Fust G, et al. Hereditary angioedema: a decade of human $\mathrm{C} 1$-inhibitor concentrate therapy. J Allergy Clin Immunol. 2007;120(4):941-947.

23. Bork K, Witzke G. Long-term prophylaxis with C1-inhibitor (C1 INH) concentrate in patients with recurrent angioedema caused by hereditary and acquired C1-inhibitor deficiency. J Allergy Clin Immunol. 1989;83(3):677-682.

24. Levi M, Choi G, Picavet C, Hack CE. Self-administration of C1-inhibitor concentrate in patients with hereditary or acquired angioedema caused by C1-inhibitor deficiency. J Allergy Clin Immunol. 2006;117(4):904-908.

25. Zuraw B, Busse P, White M, et al. Efficacy and safety of long-term prophylaxis with $\mathrm{C} 1$-inhibitor $(\mathrm{C} 1 \mathrm{INH})$ concentrate in patients with hereditary angioedema (HAE). [Abstract] AAAAI poster presentation, Philadelphia USA; 2008.

26. Hack CE. C1-inhibitor: Antigenic and Functional analysis. In: Morgan BP, ed. Methods in Molecular Biology Totowa. NJ: Humana Press; 1998:159-172.

27. Bork K, Fischer B, Dewald G. Recurrent episodes of skin angioedema and severe attacks of abdominal pain induced by oral contraceptives or hormone replacement therapy. Am J Med. 2003;114(4):294-298.

28. Bork K, Barnstedt SE. Laryngeal edema and death by asphyxiation following tooth extraction in four patients with hereditary angioedema. J Am Dent Assoc. 2003;134(8):1088-1094.

29. Farkas H, Fust G, Fekete B, Karadi I, Varga L. Eradication of Helicobacter pylori and improvement of hereditary angioneurotic oedema. Lancet. 2001;358(9294):1695-1696.

30. Visy B, Fust G, Bygum A, Bork K, Longhurst H, Bucher C, et al. Helicobacter pylori infection as a triggering factor of attacks in patients with hereditary angioedema. Helicobacter. 2007;12(3):251-257. 
31. Agostoni A. Inherited $\mathrm{C} 1$ inhibitor deficiency. Complement Inflamm. 1989;6:112-118.

32. Davis AE III. The pathophysiology of hereditary angioedema. Clin Immunol. 2005;114(1):3-9.

33. Nussberger J, Cugno M, Amstutz C, Cicardi M, Pellacani A, Agostoni A. Plasma bradykinin in angio-oedema. Lancet. 1998; 351(9117):1693-1697.

34. Nussberger J, Cugno M, Cicardi M, Agostoni A. Local bradykinin generation in hereditary angioedema. J Allergy Clin Immunol. 1999;104(6):1321-1322.

35. Nussberger J, Cugno M, Cicardi M. Bradykinin-mediated angioedema. N Engl J Med. 2002;347(8):621-622.

36. Pappalardo E, Zingale LC, Terlizzi A, Zanichelli A, Folcioni A, Cicardi M. Mechanisms of C1-inhibitor deficiency. Immunobiology. 2002;205(4-5):542-551.

37. Zahedi R, Wisnieski J, Davies AE III. Role of the P2 residue of complement 1 inhibtior (Ala443) in determination of target protease specificity. Inhibition of complement and contact system proteases. J Immunol. 1997;159:983-988.

38. Bowen T, Cicardi M, Bork K, Zuraw B, Frank M, Ritchie B, et al. Hereditary angiodema: a current state-of-the-art review, VII: Canadian Hungarian 2007 International Consensus Algorithm for the Diagnosis, Therapy, and Management of Hereditary Angioedema. Ann Allergy Asthma Immunol. 2008;100(1 Suppl 2):S30-S40.

39. Gompels MM, Lock RJ, Abinun M, Bethune CA, Davies G, Grattan C, et al. C1 inhibitor deficiency: consensus document. Clin Exp Immunol. 2005;139(3):379-394.

40. Committee for Medicinal Products for Human Use (CHMP) of the European Medicines Evaluation Agency. CHMP assessment report for Firazyr. 11-7-2008. Accessed on October 10, 2009. Available from: http://www.emea.europa.eu/humandocs/PDFs/EPAR/firazyr/H-899eu6.pdf.

41. Cruden N, Newport M. Therapeutic potential of icatibant (HOE-140, JE-049). Expert Opin Pharmacother. 2008;9(13):1-8.

42. Bork K, Frank J, Grundt B, Schlattmann P, Nussberger J, Kreuz W. Treatment of acute edema attacks in hereditary angioedema with a bradykinin receptor-2 antagonist (Icatibant). J Allergy Clin Immunol. 2007 Jun;119(6):1497-1503.

43. Bork K, Frank J, Grundt B, Schlattmann P, Nussberger J, Kreuz W. Treatment of acute edema attacks in hereditary angioedema with a bradykinin receptor-2 antagonist (Icatibant). J Allergy Clin Immunol. 2007;119(6):1497-1503.

44. Bas M, Bier H, Greve J, Kojda G, Hoffmann TK. Novel Pharmacotherapy of acute hereditary angioedema wiht bradykinin B2-receptor antagonist icatibant. Allergy. 2006;61(12):1490-1492.

45. Cicardi M, Banerji A, Bracho F, et al. Icatibant, a new bradykininreceptor antagonist, in hereditary angioedema. $N$ Engl $J$ Med. 2010;363:532-541.

46. Malbrán A, Di Marco P, Romero F. Treatment of hereditary angioedema with icatibant. Report of 163 attacks. [Abstract] Presented at the 6th European C1inhibitor deficiency workshop, Budapest; 2009.
47. Reshef A, Leibovich I, Goren A. Hereditary Angioedema: New Hopes for an Orphan Disease. Isr Med Assoc J. 2009;10:850-855.

48. Bright P, Gompels M, Dempster J, Longhurst H. Case series: UK experience of icatibant for acute attacks of hereditary angioedema. Presented at EAACI summer school, Norwich. 9 A.D. Jul 24; 2009.

49. Bright P, Dempster J, Longhurst H. Case report: successful treatment of acquired C1 inhibitor deficiency with icatibant-submitted. 2009.

50. Dewald G, Bork K. Missense mutations in the coagulation factor XII (Hageman factor) gene in hereditary angioedema with normal $\mathrm{C} 1$ inhibitor. Biochem Biophys Res Commun. 2006;343(4):1286-1289.

51. Lehmann A. Ecallantide (DX-88), a plasma kallikrein inhibitor for the treatment of hereditary angioedema and the prevention of blood loss in on-pump cardiothoracic surgery. Expert Opin Biol Ther. 2008;8(8):1187-1199.

52. Choi G, Soeters MR, Farkas H, Varga L, Obtulowicz K, Bilo B, et al. Recombinant human $\mathrm{C} 1$-inhibitor in the treatment of acute angioedema attacks. Transfusion. 2007;47(6):1028-1032.

53. Longhurst $\mathrm{H}$. Rhucin, a recombinant $\mathrm{C} 1$ inhibitor for the treatment of hereditary angioedema and cerebral ischemia. Curr Opin Investig Drugs. 2008;9(3):310-323.

54. van Doorn MB, Burggraaf J, van DT, Eerenberg A, Levi M, Hack CE, et al. A phase I study of recombinant human $\mathrm{C} 1$ inhibitor in asymptomatic patients with hereditary angioedema. J Allergy Clin Immunol. 2005;116(4):876-883.

55. Longhurst HJ, Carr S, Khair K. C1-inhibitor concentrate home therapy for hereditary angioedema: a viable, effective treatment option. Clin Exp Immunol. 2007;147(1):11-17.

56. Kreuz W, Martinez-Saguer I, Aygoren-Pursun E, Rusicke E, Heller C, Klingebiel T. C1-inhibitor concentrate for individual replacement therapy in patients with severe hereditary angioedema refractory to danazol prophylaxis. Transfusion. 2009;49(9):1987-1995.

57. Bygum A, Andersen KE, Mikkelsen CS. Self-administration of intravenous $\mathrm{C} 1$-inhibitor therapy for hereditary angioedema and associated quality of life benefits. Eur J Dermatol. 2009;19(2):147-151

58. Caballero T, Lopez-Serrano C. Anaphylactic reaction and antibodies to DX-88 (kallikrein inhibitor) in a patient with hereditary angioedema (letter). J Allergy Clin Immunol. 2006;11(7):476-477.

59. Farkas H, Varga L, Szeplaki G, Visy B, Harmat G, Bowen T. Management of hereditary angioedema in pediatric patients. Pediatrics. 2007;120(3):e713-e722.

60. Bouillet L, Longhurst H, Boccon-Gibod I, Bork K, Bucher C, Bygum A, et al. Disease expression in women with hereditary angioedema. Am J Obstet Gynecol. 2008;199(5):484.

61. Cicardi M, Zingale LC, Zanichelli A, Deliliers DL, Caccia S. The use of plasma-derived $\mathrm{C} 1$ inhibitor in the treatment of hereditary angioedema. Expert Opin Pharmacother. 2007;8(18):3173-3181.

62. Longhurst HJ. Emergency treatment of acute attacks in hereditary angioedema due to $\mathrm{C} 1$ inhibitor deficiency: what is the evidence? Int $J$ Clin Pract. 2005;59(5):594-599.
Vascular Health and Risk Management

\section{Publish your work in this journal}

Vascular Health and Risk Management is an international, peerreviewed journal of therapeutics and risk management, focusing on concise rapid reporting of clinical studies on the processes involved in the maintenance of vascular health; the monitoring, prevention and treatment of vascular disease and its sequelae; and the involvement of

\section{Dovepress}

metabolic disorders, particularly diabetes. This journal is indexed on PubMed Central and MedLine. The manuscript management system is completely online and includes a very quick and fair peer-review system, which is all easy to use. Visit http://www.dovepress.com/ testimonials.php to read real quotes from published authors. 